Article

\title{
Arterial Function in Healthy Pregnant Women vs. Non-Pregnant Women-A 10-Year Study
}

\author{
Vladiana Turi ${ }^{1}$, Simona Dragan ${ }^{1}$, Mircea Iurciuc ${ }^{1}$, Lavinia Moleriu ${ }^{2}$, Simona Bungau ${ }^{3, *(D)}$, \\ Delia Mirela Tit ${ }^{3}$ (D), Daniela-Oana Toader ${ }^{4,5}$, Camelia Cristina Diaconu ${ }^{6,7}$, Tapan Behl ${ }^{8}$ and \\ Izabella Petre ${ }^{9}$
}

1 Department of Cardiology, “Victor Babeş” University of Medicine and Pharmacy, 2 Eftimie Murgu Sq., 300041 Timisoara, Romania; turi.vladiana@umft.ro (V.T.); simona.dragan@umft.ro (S.D.); mirceaiurciuc@gmail.com (M.I.)

2 Department III Functional Sciences, Faculty of Medicine, "Victor Babes" University of Medicine and Pharmacy, 2 Eftimie Murgu Sq., 300041 Timisoara, Romania; moleriu.lavinia@umft.ro

3 Department of Pharmacy, Faculty of Medicine and Pharmacy, University of Oradea, 29 N. Jiga St., 410028 Oradea, Romania; mirela_tit@yahoo.com

4 Department 13, Faculty of Medicine, "Carol Davila" University of Medicine and Pharmacy, 050474 Bucharest, Romania; oana.toader@yahoo.com

5 "Alessandrescu-Rusescu" National Institute for Mother and Child Health, Bucharest, Polizu Clinical Hospital, 011062 Bucharest, Romania

6 Department 5, Faculty of Medicine, "Carol Davila" University of Medicine and Pharmacy, 050474 Bucharest, Romania; drcameliadiaconu@gmail.com

7 Department of Internal Medicine, Clinical Emergency Hospital of Bucharest, 014461 Bucharest, Romania

8 Chitkara College of Pharmacy, Chitkara University, Punjab 140401, India; tapanbehl31@gmail.com

9 Department XII of Obstetrics and Gynaecology, "Victor Babeş” University of Medicine and Pharmacy, 2 Eftimie Murgu Sq., 300041 Timisoara, Romania; dr.petreizabella@yahoo.com

* Correspondence: sbungau@uoradea.ro; Tel.: +40-726-776-588

Received: 24 May 2020; Accepted: 3 June 2020; Published: 5 June 2020

\begin{abstract}
Introduction. Maternal age for the first pregnancy is increasing and so, the prevalence of cardiovascular risk factors in pregnancy is also increasing. Heart disease is the main reason for maternal death during pregnancy in developed countries. Arterial stiffness is an independent risk factor for atherosclerosis and a predictor of cardiovascular morbidity and mortality. The most widespread parameters for detecting subclinical atherosclerosis are augmentation index (AIx) and pulse wave velocity (PWV). The objective of this prospective study was to assess the differences between arterial function in pregnant vs. non-pregnant women of the same age, and its changes throughout the gestation period. Materials and Methods. Between 2010-2019, 887 patients were enrolled into 2 groups: pregnant $(\mathrm{N} 1=471)$ and non-pregnant $(\mathrm{N} 2=416)$. Data about their anthropometric characteristics, arterial function (for group 1 in all three trimesters and 6 weeks post-partum), smoking status and physical activity were collected. Results. There were statistically significant differences $(p<\alpha, \alpha=0.05)$ between the two groups regarding the body mass index, brachial AIx, systolic, diastolic and central blood pressure, and pulse pressure values. In the first group, there was a decrease of both brachial AIx and PWV in the second and third trimester, followed by a post-partum increase; better outcomes were noticed in physically active women. Conclusions. Arterial function modifies during pregnancy and these alterations differ according to the trimester of gestation. Further research is needed to establish the cut-off values for this category. Pregnant women can have better outcomes through physical activity.
\end{abstract}

Keywords: arterial stiffness; pulse wave velocity; augmentation index; pregnancy; cardiovascular risk 


\section{Introduction}

Cardiovascular disease is associated with increased arterial stiffness and central aortic systolic blood pressure (SBPao) [1]. The first sign of vascular dysfunction and atherosclerosis is represented by arterial stiffening, which can be assessed through pulse wave velocity (PWV), a simple, non-invasive, and reliable parameter [2]. It is optimal to recognise subclinical atherosclerosis in asymptomatic populations and take action before clinical manifestations of cardiovascular diseases occur and to stratify the risk accordingly [3]. PWV has the advantage and potential to be utilised in the general population, and an enhancement in the capability of identifying high-risk patients would lead to improved stratification and more effective preventive therapy [4].

Arterial stiffness describes properties of the arterial vascular system such as distensibility, compliance, and elastic modulus [5]. It can be assessed at different sites, such as systemically (pulse wave analysis), regionally (PWV), or locally (relating a change in the area of an artery to distending pressure) [6]. PWV measures the distance travelled by the pulse wave over time, has the best predictive value for cardiovascular events and the simplicity of its measurement makes it a gold standard for assessing arterial stiffness in daily practice [7]. Among stiffness parameters, PWV is the most studied, and its predictive accuracy has been demonstrated in a number of studies [8].

Physiological pregnancy has a shifting effect on the cardiovascular system, which is maintained into the post-partum period [9]. At around five weeks of gestation, there is a systemic and renal vasodilatation; then, the systemic vascular resistance (SVR) decreases progressively (by $35-40 \%$ ) until the middle of the second trimester, when it plateaus before beginning to increase late in the third trimester [10]. Endothelium-dependent vasodilatation and brachial artery diameter enhancement occur in healthy pregnancies [11]. Vasodilation causes a drop-in mean arterial pressure associated with increased cardiac output (from 20 to 50\%) and plasma volume [12], due to the stroke volume increase of about $25 \%$ in the first trimester. This considerable increase in the cardiac output is one reason why pregnant women with pre-existing heart conditions can experience dramatic effects, especially later on. Arterial stiffness may be a measure of the degree of plasma volume expansion [13]. These changes are often hemodynamic, counter-regulatory and still maintain the basic vascular principles of keeping the new mean arterial pressure of pregnancy [14]; they are supposed to be caused by the attachment of the placenta to uterine walls, which induces the release of hormones and subsequent changes to maternal physiology [14]. Hormonal changes include an increased rate of release of vasodilators in the maternal female, such as prostaglandins and nitric oxide [15], and a decreased responsiveness of maternal vasculature to angiotensin II and norepinephrine [16].

Systemic vasodilation and physiologic anaemia lead to tachycardia (heart rate increases by $15-30 \%$ in the first trimester of pregnancy) and contribute to a further cardiac output augmentation [17]. Blood pressure slightly decreases early in pregnancy, due to incomplete compensation of cardiac output, and is more pronounced for the diastolic component, which returns to normal or even exceeds baseline values [18].

There are proofs regarding the contribution of maternal arterial dysfunction in pregnancy-specific conditions such as preeclampsia and intrauterine growth restriction [19]. Arterial stiffness is positively associated with hypertension [20], stroke [21], heart failure, and ischemic artery disease [22], with an increase in the risk of a first major cardiovascular event [23], which is the main cause of death in pregnant women in developed countries [24]. Arterial stiffness is an independent risk factor for atherosclerosis and a predictor of cardiovascular morbidity and mortality [25]. The Framingham Heart Study concluded that elevated stiffness correlates with an increased probability for a major cardiovascular event [26]. In the Rotterdam Study, it was observed that arterial stiffness independently predicts stroke and coronary heart disease in healthy normotensive patients [27]. In addition, the arterial stiffness is related to the foetus and neonatal outcomes as well. Similar to arterial stiffness, low birth weight is a predictor for cardiovascular morbidity and mortality [28].

The predictive value of PWV for cardiovascular diseases (CVD) has been studied and reported in the general population and in patients with different clinical conditions [2]. The information regarding 
the clinical significance of arterial distensibility assessment in young to middle age pregnant women is missing. Arterial function parameters could be useful tools to detect early modifications in the vascular function of pregnant patients before clinical manifestations and further complications occur in both mother and foetus. They could also serve for the assessment of therapeutic results. The lack of reference values in pregnant patients limits their applicability in clinical practice.

In the general population, arterial stiffness is an early marker of cardiovascular disease and a predictor for mortality. During pregnancy, the entire cardiovascular system suffers modifications, including the arterial stiffness and compliance parameters. These alterations are more extensive and prolonged in preeclampsia patients. Arterial stiffness enhancement precedes the onset of pregnancy-related hypertensive disorders. Its parameters can be used as early risk detectors in normotensive, low-risk women who will develop preeclampsia.

The current study aimed to compare arterial stiffness in pregnant and non-pregnant women and assess the differences. There are no reference values for gestational period and previous research was based on numbers for the general population. In all pregnant patients with pregnancy-related diseases, chronic conditions prior to gestation, or risk factors, or even healthy women, it is necessary to assess their arterial stiffness parameters as predictors for possible future events. It is mandatory to thoroughly study the arterial stiffness before, during and after gestation on large groups of subjects and to establish the exact cut-off values for this population.

\section{Materials and Methods}

\subsection{Study Design}

This prospective study was performed in patients admitted to the Obstetrics and Gynaecology Department of "Pius Brînzeu" Emergency Clinical County Hospital of Timisoara, Romania, during a 10-year period (between 2010-2019). The study was performed with the approval of the Ethics Committee of the hospital mentioned above (decision no. 54/20 April 2017) and it was conducted according to the established principles of the Declaration of Helsinki [29].

First, 1000 patients were included in the study. Patients with high blood pressure, cardiac arrhythmias, diabetes, obesity, hypercholesterolemia, chronic kidney disease, and systemic vasculitis, were excluded from the study. The final group consisted of 887 pregnant and non-pregnant healthy women, aged between 20-45 years, after they signed the informed consent.

The patients were divided into two different groups: group 1-healthy primiparous pregnant patients $(\mathrm{N} 1=471,53.1 \%)$, without comorbidities or risk factors and group 2-control, healthy non-pregnant patients (N2 $=416,46.9 \%)$. Figure 1 presents the flow chart of the study.

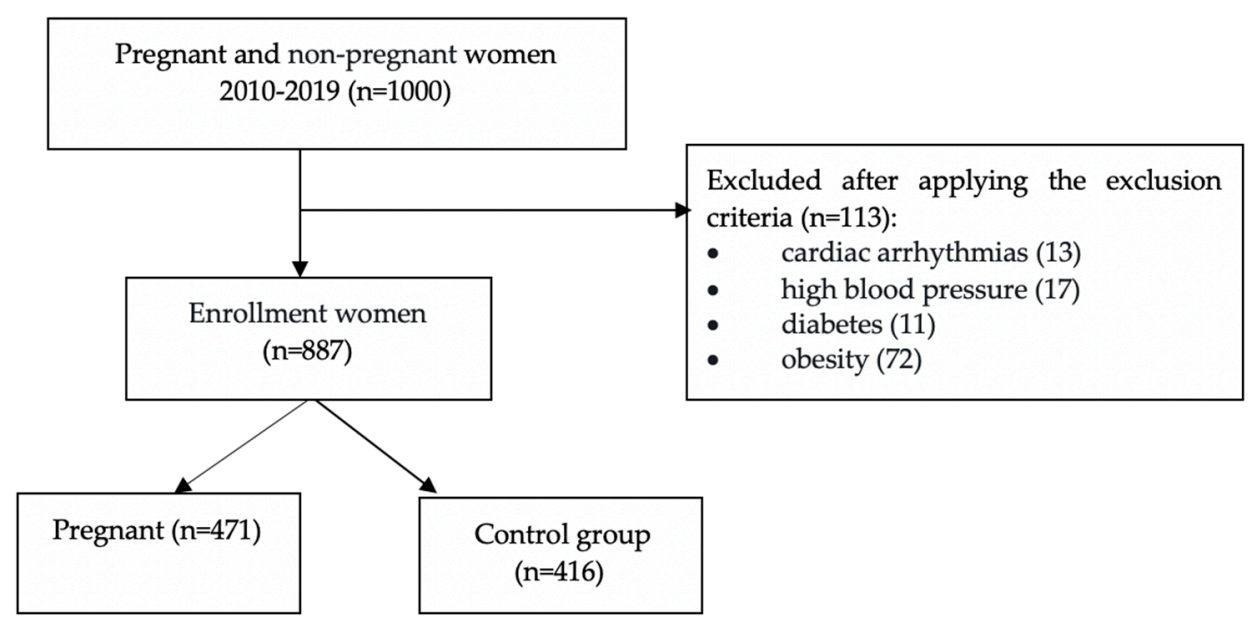

Figure 1. Flow chart of the study. 
Personal data about lifestyle, smoking status, exercise, medical history (including family history), anthropometric features (such as age, height, weight, body mass index (BMI)) and results of arterial function assessments were collected. In group 1 (healthy pregnant), data about arterial functions were collected during four separate visits, in the first, second and third trimester of pregnancy, and 6 weeks post-delivery. In addition, data about the gestational period, the foetus weight and gender and delivery type (vaginal or caesarean) were added.

\subsection{Paraclinical Evaluation}

The pulse wave was analysed through an easy, non-invasive method and an accredited medical device: Arteriograph (TensioMed, Hungary). Each patient was prepared $24 \mathrm{~h}$ prior to the test, and the procedure was explained (according to the "patient info" document). For PWV determination, the protocol from the technical book [30] of the device was followed.

The room/doctor's office offered a proper environment (no noises, temperature of $22-25^{\circ} \mathrm{C}$ ); the consultation bed was a horizontally fitted mattress with easy access to both arms. Patients who smoked, ate, drank energy drinks/coffee within $<3 \mathrm{~h}$ prior to the assessment were rescheduled. The patient was laid down to rest for approximatively 10-20 min before the investigation. After the patient was set in the supine position, tight clothing was removed from forearms and arms. The circumference of both arms and the distance between the pubic symphysis and the sternum fork were measured. Personal information, anthropometric characteristics and anamnesis data were registered. The cuff recommended by the software $(1,2$ or 3$)$ was placed in the middle of the arm and the measurements were performed. The patient was not allowed to speak, sleep or move throughout the investigation, and remained in the supine position. If the investigation values appeared erroneous, or the patient was emotional or had tachycardia, the assessment was repeated 4 times (1-2 min intervals between measurements) on the same arm. The cuff was shifted to the contralateral arm (observing the size of the cuff according to the software recommendation) if the expected results were not obtained. If no results were obtained on the contralateral arm as well, manual measurements were performed, as allowed by the software. In the case of arrhythmias, the investigation was postponed until sinus rhythm was established and performed only in hemodynamic stability, with properly controlled values (according to the European Society of Cardiology guidelines) [30]. Patients who had pathological results were informed about their outcomes and referred to a cardiologist. The result of the determination was General Data Protection Regulation (GDPR) compliant [31].

According to the data from the literature, the reference value of PWV in adult women is $7.4 \mathrm{~m} / \mathrm{s}$ [32]. Reference values are lower in young, healthy women $(6.1(4.6-7.5) \mathrm{m} / \mathrm{s}))$, and gradually increase with age and blood pressure. Reference values for PWV [33] in the general population are presented in Table 1.

Table 1. PWV reference values $(\mathrm{m} / \mathrm{s})$ in the general population according to the age category.

\begin{tabular}{ccc}
\hline Age Category (Years) & Mean (+2 SD) & Median (10-90 pc) $* *$ \\
\hline$<30$ years & $6.2(4.7-7.6)$ & $6.1(5.3-7.1)$ \\
30-39 years & $6.5(3.8-9.2)$ & $6.4(5.2-8.0)$ \\
$40-49$ & $7.2(4.6-9.8)$ & $6.9(5.9-8.6)$ \\
$50-59$ & $8.3(4.5-12.1)$ & $8.1(6.3-10.0)$ \\
$60-69$ & $10.3(5.5-15.0)$ & $9.7(7.9-13.1)$ \\
$\geq 70$ & $10.9(5.5-16.3)$ & $10.6(8.0-14.6)$ \\
\hline
\end{tabular}

*SD, standard deviation; ${ }^{* *} 10 \mathrm{pc}$, the upper limit of the 10 th percentile; $90 \mathrm{pc}$, the lower limit of the 90 th percentile.

The complex arterial function assessment included parameters such as systolic blood pressure (SBP), diastolic blood pressure (DBP), pulse pressure (PP), heart rate (HR), aortic SBP (SBPao), aortic pulse wave velocity (PWVao), and augmentation index (AIx). All measurements were performed with the same device, TensioMed Arteriograph, mentioned before. 


\subsection{Statistical Analysis}

The database was created using the Microsoft Excel program. For testing the data distribution, the Kolmogorov-Smirnov normality test was applied. To see if the observed differences were statistically significant, the most suitable statistical tests for our variables, the $t$ Student test, Mann-Whitney test, ANOVA unifactorial test and Friedman test were used. For the entire study, $\alpha=0.05$ was considered as the confidence level. For descriptive statistics, the central tendency and dispersion indicators were calculated, and the main results were plotted. The statistical analysis was performed using the SPSSv17 and the Microsoft Excel programs.

\section{Results}

For the qualitative dichotomous variables, frequency tables were used. The mean values for basic characteristics and hemodynamic parameters in both groups are presented in Table 2.

Table 2. Anthropometric, haemodynamic and arterial stiffness characteristics of both groups (group 1, N1 = 471—healthy pregnant patients; group 2, N2 = 416—control group).

\begin{tabular}{|c|c|c|c|c|c|c|c|c|c|}
\hline Statistics & Age & $\begin{array}{c}\text { BMI } \\
\left(\mathrm{Kg} / \mathrm{m}^{2}\right)\end{array}$ & $\begin{array}{c}\text { SBP } \\
(\mathrm{mmHg})\end{array}$ & $\begin{array}{c}\text { DBP } \\
(\mathrm{mmHg})\end{array}$ & $\begin{array}{c}\text { PP } \\
\text { (mmHg) }\end{array}$ & $\begin{array}{l}\text { SBPao } \\
(\mathrm{mmHg})\end{array}$ & $\begin{array}{c}\text { HR } \\
(1 / \mathrm{min})\end{array}$ & $\begin{array}{l}\text { Brachial } \\
\text { AIx (\%) }\end{array}$ & $\begin{array}{c}\text { PWVao } \\
(\mathrm{m} / \mathrm{s})\end{array}$ \\
\hline \multirow{2}{*}{ Mean } & 30.15 & 21.43 & 122.30 & 72.62 & 49.68 & 115.21 & 72.28 & -47.41 & 6.78 \\
\hline & 29.61 & 21.43 & 122.59 & 74.72 & 47.87 & 109.16 & 71.57 & -49.50 & 7.43 \\
\hline \multirow{2}{*}{ Standard error } & 0.24 & 0.10 & 0.49 & 0.28 & 0.30 & 0.14 & 0.16 & 0.20 & 0.01 \\
\hline & 0.22 & 0.09 & 0.42 & 0.30 & 0.28 & 0.55 & 0.48 & 0.79 & 0.02 \\
\hline \multirow{2}{*}{ Median } & 27 & 20.76 & 130 & 75 & 54 & 116 & 73 & -47.47 & 6.81 \\
\hline & 31 & 21.36 & 122 & 75 & 48 & 110 & 71 & -50.7 & 7.4 \\
\hline \multirow{2}{*}{ Mode } & 27 & 19.96 & 130 & 75 & 55 & 116 & 73 & -52.6 & 6.78 \\
\hline & 32 & 22.58 & 130 & 80 & 40 & 119 & 68 & -34.5 & 7.4 \\
\hline \multirow{2}{*}{$\begin{array}{l}\text { Standard } \\
\text { deviation }\end{array}$} & 5.22 & 2.27 & 10.72 & 6.06 & 6.51 & 3.11 & 3.49 & 4.36 & 0.16 \\
\hline & 4.39 & 1.86 & 8.64 & 6.09 & 5.69 & 11.22 & 9.75 & 16.20 & 0.49 \\
\hline \multirow{2}{*}{ Sample variance } & 27.24 & 5.14 & 114.98 & 36.70 & 42.35 & 9.66 & 12.17 & 19.02 & 0.02 \\
\hline & 19.26 & 3.47 & 74.60 & 37.12 & 32.33 & 125.80 & 95.14 & 262.60 & 0.24 \\
\hline \multirow{2}{*}{ Kurtosis } & -0.79 & -0.87 & 0.19 & -0.06 & -0.20 & 0.81 & 0.11 & -1.25 & 6.17 \\
\hline & 0.30 & -0.81 & -0.94 & -0.58 & -0.86 & 0.04 & 0.03 & 0.45 & 7.95 \\
\hline \multirow{2}{*}{ Skewness } & 0.77 & 0.50 & -1.15 & -0.05 & -0.94 & -0.95 & -0.68 & -0.04 & -2.18 \\
\hline & 0.11 & 0.19 & 0.04 & -0.05 & 0.28 & 0.04 & 0.45 & 0.41 & 2.26 \\
\hline \multirow{2}{*}{ Range } & 25 & 9.65 & 36 & 25 & 26 & 13 & 16 & 17 & 0.92 \\
\hline & 25 & 7.52 & 34 & 30 & 20 & 56 & 53 & 101.6 & 3 \\
\hline \multirow{2}{*}{ Minimum } & 20 & 17.30 & 94 & 60 & 29 & 107 & 63 & -57 & 6.09 \\
\hline & 20 & 18.20 & 108 & 62 & 40 & 82 & 52 & -85.9 & 6.7 \\
\hline \multirow{2}{*}{ Maximum } & 45 & 26.95 & 130 & 85 & 55 & 120 & 79 & -40 & 7.01 \\
\hline & 45 & 25.71 & 142 & 92 & 60 & 138 & 105 & 15.7 & 9.7 \\
\hline
\end{tabular}

Data for the group 1 were highlighted in grey.

To determine if there are any significant differences between both groups and between subjects who performed physical activity and who did not, several statistical tests were used. The Kolmogorov-Smirnov normality test was applied to see the data distribution for the numerical variables, and a normal distribution for all data was found $(p<0.05)$; thus, parametrical tests were valid. For double-checking, one parametrical test (the Student $t$ unpaired test) and a nonparametric test (the Mann-Whitney test) for age, body mass index (BMI), brachial AIx, PWVao, SBP, DBP, PP (which is the difference between systolic and diastolic blood pressure), SBPao and HR values were combined. Statistically significant differences $(p<0.05)$ were obtained for BMI, brachial AIx, PWVao, DBP, PP and SBPao values. All the results are presented in Table 3. 
Table 3. The primary descriptive statistics, the $p$ values obtained using both Student $t$ unpaired test and the Mann-Whitney test, applied on the numerical variables for both groups $(\mathrm{N} 1=471, \mathrm{~N} 2=416$ ).

\begin{tabular}{|c|c|c|c|c|c|c|c|}
\hline \multicolumn{2}{|c|}{$\begin{array}{l}\text { Statistics } \rightarrow \\
\text { Variables } \downarrow\end{array}$} & \multirow{3}{*}{$\begin{array}{c}\text { Group } \\
1 \\
2\end{array}$} & \multirow{3}{*}{$\begin{array}{l}\text { Mean } \\
30.15 \\
29.61\end{array}$} & \multirow{3}{*}{$\begin{array}{c}\begin{array}{c}\text { Standard } \\
\text { Deviation }\end{array} \\
5.2 \\
4.39\end{array}$} & \multirow{3}{*}{$\begin{array}{c}\text { Std. Error } \\
\text { Mean }\end{array}$} & \multirow{3}{*}{$\begin{array}{c}p \text { Value } \\
t \text {-Test }\end{array}$} & \multirow{3}{*}{$\begin{array}{c}\begin{array}{c}p \text { Value } \\
\text { Mann-Whitney }\end{array} \\
0.607\end{array}$} \\
\hline Age & & & & & & & \\
\hline Age & Years & & & & & & \\
\hline \multirow{2}{*}{ BMI } & \multirow{2}{*}{$\mathrm{Kg} / \mathrm{m}^{2}$} & 1 & 21.42 & 2.2 & 0.1045 & \multirow{2}{*}{$<0.001 *$} & \multirow{2}{*}{$0.034 *$} \\
\hline & & 2 & 21.43 & 1.86 & 0.09 & & \\
\hline \multirow{2}{*}{ Brachial AIx } & \multirow{2}{*}{$\%$} & 1 & -47.41 & 4.36 & 0.20 & \multirow{2}{*}{$0.011^{*}$} & \multirow{2}{*}{$0.012 *$} \\
\hline & & 2 & -49.50 & 16.20 & 0.79 & & \\
\hline \multirow{2}{*}{ PWVao } & \multirow{2}{*}{$\mathrm{m} / \mathrm{s}$} & 1 & 6.77 & 0.157 & 0.007 & \multirow{2}{*}{$<0.001^{*}$} & \multirow{2}{*}{$<0.001 *$} \\
\hline & & 2 & 7.43 & 0.49 & 0.023 & & \\
\hline \multirow{2}{*}{ SBP } & \multirow{6}{*}{$(\mathrm{mm} \mathrm{Hg})$} & 1 & 122.30 & 10.723 & 0.494 & \multirow{2}{*}{$<0.001^{*}$} & \multirow{2}{*}{$<0.001^{*}$} \\
\hline & & 2 & 122.59 & 8.64 & 0.42 & & \\
\hline \multirow{2}{*}{ DBP } & & 1 & 72.62 & 6.058 & 0.279 & \multirow{2}{*}{$<0.001^{*}$} & \multirow{2}{*}{$<0.001^{*}$} \\
\hline & & 2 & 74.72 & 6.09 & 0.3 & & \\
\hline \multirow{2}{*}{$\mathrm{PP}$} & & 1 & 49.68 & 6.507 & 0.300 & \multirow{2}{*}{$<0.001^{*}$} & \multirow{2}{*}{$<0.001 *$} \\
\hline & & 2 & 47.87 & 5.69 & 0.28 & & \\
\hline \multirow{2}{*}{ SBPao } & & 1 & 115.21 & 3.108 & 0.143 & \multirow{2}{*}{$<0.001 *$} & \multirow{2}{*}{$<0.001 *$} \\
\hline & & 2 & 109.16 & 11.22 & 0.55 & & \\
\hline \multirow[t]{2}{*}{$\mathrm{HR}$} & \multirow{2}{*}{$1 / \mathrm{min}$} & 1 & 72.28 & 3.488 & 0.161 & \multirow{2}{*}{$<0.001 *$} & \multirow{2}{*}{$<0.001 *$} \\
\hline & & 2 & 71.57 & 9.75 & 0.48 & & \\
\hline
\end{tabular}

* Statistically significant differences $(p<0.05)$.

In pregnant women, brachial AIx decreased progressively during pregnancy and increased again in post-partum (the mean value in the first trimester was $-47.41 \% \pm \mathrm{SD}$, in the second trimester it was $-51.93 \% \pm \mathrm{SD}$, and in the third it was $-58.40 \% \pm \mathrm{SD}$; in post-partum, it increased to $-45.57 \% \pm \mathrm{SD}$ ). PWVAo started to decline in the second trimester and continued to decline in the third trimester; in post-partum, it was increased compared to the first trimester (mean PWVAo in the first trimester was $6.78 \mathrm{~m} / \mathrm{s} \pm \mathrm{SD}$, in the second trimester $5.99 \mathrm{~m} / \mathrm{s} \pm \mathrm{SD}$ and in the last trimester $5.93 \mathrm{~m} / \mathrm{s} \pm \mathrm{SD}$; in post-partum it increased to $7.17 \mathrm{~m} / \mathrm{s} \pm \mathrm{SD}$ ) (Table 4 ).

Table 4. The central tendency and dispersion indicators calculated on arterial stiffness characteristics for group 1 (healthy pregnant patients, $\mathrm{N} 1=471$ ).

\begin{tabular}{|c|c|c|c|c|c|c|c|c|}
\hline Statistics & $\begin{array}{c}\text { Brachial } \\
\text { AIx } \\
(\%)\end{array}$ & $\begin{array}{c}\text { PWVao } \\
(\mathrm{m} / \mathrm{s})\end{array}$ & $\begin{array}{c}\text { Brachial } \\
\text { AIx } \\
(\%)\end{array}$ & $\begin{array}{c}\text { PWVao } \\
(\mathrm{m} / \mathrm{s})\end{array}$ & $\begin{array}{c}\text { Brachial } \\
\text { AIx } \\
(\%)\end{array}$ & $\begin{array}{c}\text { PWVao } \\
(\mathrm{m} / \mathrm{s})\end{array}$ & $\begin{array}{c}\text { Brachial } \\
\text { AIx } \\
(\%)\end{array}$ & $\begin{array}{c}\text { PWVao } \\
(\mathrm{m} / \mathrm{s})\end{array}$ \\
\hline & \multicolumn{2}{|c|}{ 1st trimester } & \multicolumn{2}{|c|}{ 2nd trimester } & \multicolumn{2}{|c|}{ 3rd trimester } & \multicolumn{2}{|c|}{ Post-partum } \\
\hline Mean & -47.41 & 6.78 & -51.93 & 5.99 & -58.40 & 5.93 & -45.57 & 7.17 \\
\hline Standard error & 0.20 & 0.01 & 0.11 & 0.02 & 0.22 & 0.02 & 0.16 & 0.02 \\
\hline Median & -47.47 & 6.81 & -52.18 & 6.1 & -58.45 & 6.07 & -45.16 & 7.35 \\
\hline Mode & -52.6 & 6.78 & -52.6 & 6.1 & -52.6 & 6.14 & -45.16 & 7.39 \\
\hline Standard deviation & 4.36 & 0.16 & 2.43 & 0.51 & 4.73 & 0.53 & 3.54 & 0.43 \\
\hline Sample variance & 19.02 & 0.02 & 5.89 & 0.26 & 22.37 & 0.28 & 12.51 & 0.18 \\
\hline Kurtosis & -1.25 & 6.17 & 1.86 & -1.65 & -1.41 & -1.18 & -1.38 & 4.64 \\
\hline Skewness & -0.04 & -2.18 & 0.10 & -0.04 & 0.13 & -0.31 & -0.21 & -2.43 \\
\hline Range & 17 & 0.92 & 16.3 & 1.55 & 16.46 & 1.78 & 11.28 & 1.9 \\
\hline Minimum & -57 & 6.09 & -59.3 & 5.15 & -66.15 & 4.98 & -51.5 & 5.8 \\
\hline Maximum & -40 & 7.01 & -43 & 6.7 & -49.69 & 6.76 & -40.22 & 7.7 \\
\hline
\end{tabular}

In order to see if there are significant differences in the four tested time points, the ANOVA unifactorial test and Friedman test were applied, resulting in extremely significant differences $(p<0.001)$ between the brachial AIx (\%) and PWVao values during the study period. Brachial AIx \% decreased until the third trimester, when it started to increase again until the post-partum stage (Figure 2a). PWVao decreased in the second trimester, it was maintained in the last trimester, and increased again in post-partum, even more, compared to baseline (first trimester) (Figure 2b). 


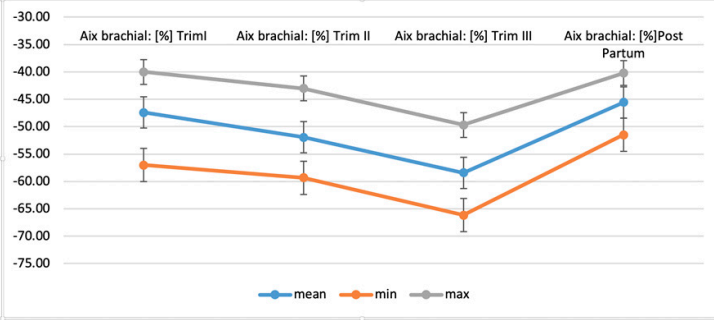

a.

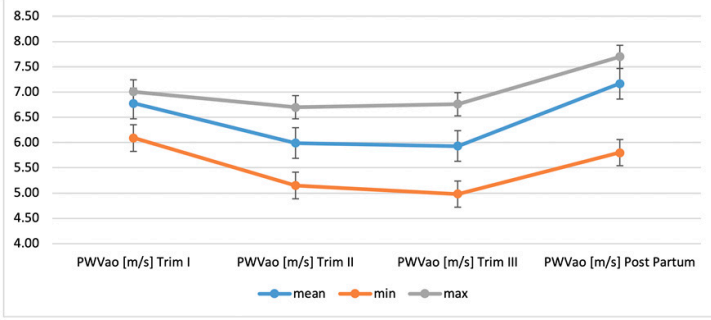

b.

Figure 2. The brachial AIx (a) and PWVao progressions (b), in group 1 (healthy pregnant patients, $\mathrm{N} 1=471)$.

The mean values for the gestational period (39.34 weeks \pm SD), APGAR score $(9.22 \pm \mathrm{SD})$ and foetus weight $(3468.97 \mathrm{~g} \pm \mathrm{SD}$ ) are presented in Table 5 . The lifestyle, habits, pregnancy and delivery outcomes, as well as foetus gender, for both groups are presented in Table 6.

Table 5. Descriptive statistics of obstetrical characteristics for group 1 (healthy pregnant patients, $\mathrm{N} 1=471)$

\begin{tabular}{cccc}
\hline Statistics & $\begin{array}{c}\text { Gestational Period } \\
\text { (Weeks) }\end{array}$ & $\begin{array}{c}\text { APGAR Score } \\
\text { at 1 } \text { min }\end{array}$ & $\begin{array}{c}\text { Foetus Weight } \\
\text { (g) }\end{array}$ \\
\hline Mean & 39.34 & 9.22 & 3468.97 \\
Standard error & 0.05 & 0.04 & 6.86 \\
Median & 39 & 9 & 3500 \\
Mode & 40 & 10 & 3500 \\
Standard deviation & 1.05 & 0.95 & 148.84 \\
Sample variance & 1.09 & 0.90 & $22,154.52$ \\
Kurtosis & 0.97 & 11.92 & -0.09 \\
Skewness & -0.30 & -2.17 & 0.18 \\
Range & 7 & 9 & 820 \\
Minimum & 35 & 1 & 3100 \\
Maximum & 42 & 10 & 3920 \\
\hline
\end{tabular}

Table 6. The frequency table according on the qualitative characteristics of both groups.

\begin{tabular}{ccccc}
\hline \multirow{2}{*}{ Variables } & \multicolumn{2}{c}{ Yes/Yes/Girl/Natural } & \multicolumn{2}{c}{ No/No/Boy/C-Section } \\
\cline { 2 - 5 } & Number & Number & \% \\
\hline Exercise & 160 & Group 1 (N1 = 471) & 66.03 \\
Smoker & 194 & 33.97 & 311 & 58.81 \\
Baby gender & 204 & 41.19 & 277 & 56.69 \\
Delivery type & 233 & 43.31 & 267 & 50.53 \\
\hline & & 49.47 & 238 & 54.09 \\
Exercise & 191 & Group 2 (Control Group, N2 = 416) & 61.54 \\
\hline Smoker & 160 & 38.46 & 225 & 256 \\
\hline
\end{tabular}

To see if physical activity can modify the outcomes, both the Student $t$ unpaired test and Mann-Whitney test were applied, for each group separately. Significant differences were obtained $(p<0.05)$ for BMI, brachial AIx, PWVao, SBP, DBP, PP, SBPao and HR values. In group 1, women who regularly exercised $(33.97 \%)$ were compared to women who did not exercise $(66.03 \%)$. We also compared them in all 4-time moments: first, second, third trimester, and in post-partum. Patients who are physically active had statistically significant better outcomes $(p<0.05)$ for delivery, anthropometric features, hemodynamic status and arterial functions. 


\section{Discussion}

PWV is an independent predictor of future CVD in women with high blood pressure [22], stroke [34], coronary artery disease [35], diabetes [36], and end-stage renal disease [37]. Reference values for pregnant women need to be established for better assessment and early detection. In the current study, healthy pregnant women had statistically significantly different values compared to healthy non-pregnant women; thus, larger prospective studies are necessary, to establish reference values for arterial function parameters for this category.

Lynch et al. highlighted the critical role of communication between physicians and pharmacists for the best outcomes of pregnancy [38]. The inter-professional team is an essential part of the healthcare system, and the need for balanced coordination of care only expands in managing the pregnant patient through a safe pregnancy for the mother and child [39].

Numerous studies have demonstrated the prognostic significance of PWVao measurement as an indicator of subclinical organ damage, both in the general population and patients with increased cardiovascular risk, especially patients with hypertension, diabetes, or chronic renal failure. Evidence suggests that aortic stiffness may precede and contribute initially to the development of hypertension [40].

In a healthy pregnancy, there is a significant increase in uterine blood flow, remodelling of the spiral arteries [41], more nitric oxide, generated from the endothelium, and enhanced overall vasodilation of the uterine vessels [42]. Women who develop preeclampsia have a decreased flow-mediated dilatation in the first and second trimesters compared to healthy pregnancies [43]. The parameters of arterial stiffness are significantly different in preeclamptic women compared to normotensive pregnancies [19] but there are no cut-off values in the literature for pregnant women.

Considering the literature data, we hypothesised that pregnant women would have a different pattern of arterial function compared to non-pregnant women. This field is yet to be explored. Some studies concluded that in physiological pregnancy, there is a significant decrease in unadjusted aortic PWV from pre-conception to the second trimester [19]. In the present research an interesting progression of the arterial markers was observed: starting from baseline (at enrolment), brachial AIx $\%$ decreased until the third trimester, and then started to increase again until the post-partum stage. PWVao decreased in the second trimester, and was maintained in the last trimester, and increased again in post-partum, even more compared to baseline (first trimester). This specific pattern should be studied in larger cohorts in the future.

Fujime et al. observed that central aortic SBP (cSBP) and AIx significantly declined during pregnancy, reaching lowest values in mid-pregnancy and rising towards term, especially the heart rate-corrected AIx (AIx-75). cSBP and AIx-75 were significantly increased in healthy pregnant women older than 35 years.

Beck et al. demonstrated that resistance and endurance exercise alone effectively reduce peripheral arterial stiffness, central blood pressure, AIx, and myocardial oxygen demand in young pre-hypertensive subjects [44]. Further on, it was demonstrated that exercise training programs improve hemodynamic parameters such as SBP, PP, SBPao, and may delay arterial ageing [45] in hypertensive populations [46]. Regarding pregnant subjects, Beetham et al. emphasized in their systematic review that sustained exercise during the third trimester appears to be safe for most healthy pregnant women [47]. This is concordant to the results of our study. In addition, physical activity improved the well-being of the previously inactive/underactive patients. Healthy pregnant women had significant benefits from regular exercise compared to sedentary healthy pregnant women $(p<0.05)$ in terms of delivery, anthropometric features, hemodynamic status and arterial functions.

Numerous pharmacological $[48,49]$ and non-pharmacological [50] solutions are able to reduce PWV and could offer an alternative for patients at high risk of CVD [51,52]. Nonetheless, further studies are necessary to confirm whether PWV reduction by this approach can directly prevent CVD in pregnant women. It is necessary to work with appropriately adjusted parameters alongside raw data. There is little information in the medical literature regarding the effects of therapy on arterial function. 
This study offers insights regarding PWV analysis and additional information about arterial stiffness in pregnant women versus conventional brachial blood pressure measurements [53]. In addition, the arterial pattern in pregnant women is different from non-pregnant women. This could be a potential base for further research regarding the importance of PWV study for the assessment, management and prediction of pregnancy-related cardiovascular events. Future perspectives include establishing exact cut-off values of arterial stiffness for healthy pregnant women and demonstrating the objective benefits of physical therapy during pregnancy in larger groups.

\section{Conclusions}

The results obtained in this study proved that arterial function is modified during pregnancy and these alterations differ according to the trimester of gestation; there was a decrease of both Aix brachial and PWV in the second and third trimester, followed by a post-partum increase. In addition, women who regularly exercised had ameliorated anthropometric features, hemodynamic status and delivery outcomes. Due to these specific changes that occur in normal healthy pregnancies, further studies are necessary to establish cut-off values for this category of patients, in order to detect early changes in arterial stiffness parameters. Arterial stiffness assessment represents a useful tool in the early diagnosis of pregnancies at risk and can lead to better routine care and better outcomes for these patients, through early detection and physical activity.

Author Contributions: All the authors have equal contribution to this paper. Conceptualization, V.T., D.M.T. and I.P.; Data curation, S.D., M.I., L.M., D.-O.T. and T.B.; Investigation, V.T., S.D., M.I., D.-O.T. and I.P.; Methodology, S.D. and C.C.D.; Software, L.M.; Supervision, S.B. and C.C.D.; Validation, S.B.; Visualization, D.-O.T.; Writing-original draft, V.T., D.M.T. and I.P.; Writing - review \& editing, V.T., S.B., D.M.T., C.C.D. and T.B. All authors have read and agreed to the published version of the manuscript.

Funding: This research received no external funding.

Conflicts of Interest: The authors declare no conflict of interest.

\section{References}

1. Khalil, A.; Akolekar, R.; Syngelaki, A.; Elkhouli, M.; Nicolaides, K.H. Maternal Hemodynamics at 11-13 Weeks' Gestation and Risk of Pre-Eclampsia. Ultrasound Obs. Gynecol. 2012, 40, 28-34. [CrossRef]

2. Kim, H.-L.; Kim, S.-H. Pulse Wave Velocity in Atherosclerosis. Front. Cardiovasc. Med. 2019. [CrossRef] [PubMed]

3. Malik, S.; Wong, N.D. Metabolic Syndrome, Cardiovascular Risk and Screening for Subclinical Atherosclerosis. Expert Rev. Cardiovasc. Ther. 2009, 7, 273-280. [CrossRef] [PubMed]

4. Liu, X.-N.; Gao, H.-Q.; Li, B.-Y.; Cheng, M.; Ma, Y.-B.; Zhang, Z.-M.; Gao, X.-M.; Liu, Y.-P.; Wang, M. Pulse Wave Velocity as a marker of Artheriosclerosis and Its Comorbidities in Chinese Patients. Hypertens. Res. 2007, 30, 237-242. [CrossRef] [PubMed]

5. Allali, J.; Chauve, C.; Denise, A.; Drevet, C.; Ferraro, P.; Gautheret, D.; Herrbach, C.; Leclerc, F.; Ouangraoua, A.; Sagot, M.-F; et al. BRASERO: A Resource for Benchmarking RNA Secondary Structure Comparison Algorithms. Adv. Bioinform. 2012, 2012, 5. [CrossRef] [PubMed]

6. Ohayon, J.; Gharib, A.M.; Garcia, A.; Heroux, J.; Yazdani, S.K.; Malvè, M.; Tracqui, P.; Martinez, M.A.; Doblare, M.; Finet, G.; et al. Is Arterial Wall-Strain Stiffening an Additional Process Responsible for Atherosclerosis in Coronary Bifurcations?: An in Vivo Study Based on Dynamic CT and MRI. Am. J. Physiol. Heart Circ. Physiol. 2011, 301, H1097-H1106. [CrossRef] [PubMed]

7. Van Bortel, L.M.; Laurent, S.; Boutouyrie, P.; Chowienczyk, P.; Cruickshank, J.K.; De Backer, T.; Filipovsky, J.; Huybrechts, S.; Mattace-Raso, F.U.S.; Protogerou, A.D.; et al. Expert Consensus Document on the Measurement of Aortic Stiffness in Daily Practice Using Carotid-Femoral Pulse Wave Velocity. J. Hypertens. 2012, 30, 445-448. [CrossRef]

8. Inoue, N.; Maeda, R.; Kawakami, H.; Shokawa, T.; Yamamoto, H.; Ito, C.; Sasaki, H. Aortic Pulse Wave Velocity Predicts Cardiovascular Mortality in Middle-Aged and Elderly Japanese Men. Circ. J. 2009, 73, 549-553. [CrossRef]

9. Stephanie, R.A.; Curtis, L. Heart Disease and Pregnancy. Cardiol. Ther. 2017, 6, 157-173. 
10. Meah, V.L.; Cockcroft, J.R.; Backx, K.; Shave, R.; Stöhr, E.J. Cardiac Output and Related Haemodynamics during Pregnancy: A Series of Meta-Analyses. Heart 2016, 102, 518-526. [CrossRef]

11. Lopes van Balen, V.A.; van Gansewinkel, T.A.G.; de Haas, S.; van Kuijk, S.M.J.; van Drongelen, J.; Ghossein-Doha, C.; Spaanderman, M.E.A. Physiological Adaptation of Endothelial Function to Pregnancy: Systematic Review and Meta-Analysis. Ultrasound Obs. Gynecol. 2017, 50, 697-708. [CrossRef] [PubMed]

12. Chapman, A.B.; Abraham, W.T.; Zamudio, S.; Coffin, C.; Merouani, A.; Young, D.; Johnson, A.; Osorio, F.; Goldberg, C.; Moore, L.G.; et al. Temporal Relationships between Hormonal and Hemodynamic Changes in Early Human Pregnancy. Kidney Int. 1998, 54, 2056-2063. [CrossRef] [PubMed]

13. Elvan-Taşpinar, A.; Franx, A.; Bots, M.L.; Koomans, H.A.; Bruinse, H.W. Arterial Stiffness and Fetal Growth in Normotensive Pregnancy. Am. J. Hypertens. 2005, 18, 337-341. [CrossRef] [PubMed]

14. Lof, M.; Olausson, H.; Bostrom, K.; Janerot-Sjöberg, B.; Sohlstrom, A.; Forsum, E. Changes in Basal Metabolic Rate during Pregnancy in Relation to Changes in Body Weight and Composition, Cardiac Output, Insulin-like Growth Factor I, and Thyroid Hormones and in Relation to Fetal Growth. Am. J. Clin. Nutr. 2005, 81, 678-685. [CrossRef] [PubMed]

15. Selzer, A. Risks of Pregnancy in Women With Cardiac Disease. JAMA J. Am. Med. Assoc. 1977, $238,892-893$. [CrossRef]

16. McFaul, P.B.; Dornan, J.C.; Lamki, H.; Boyle, D. Pregnancy Complicated by Maternal Heart Disease. A Review of 519 Women. Bjog Int. J. Obs. Gynaecol. 1988, 95, 861-867. [CrossRef]

17. Soma-Pillay, P.; Nelson-Piercy, C.; Tolppanen, H.; Mebazaa, A. Physiological Changes in Pregnancy. Cardiovasc. J. Afr. 2016, 27, 89-94. [CrossRef]

18. Ngene, N.C.; Moodley, J. Physiology of Blood Pressure Relevant to Managing Hypertension in Pregnancy. J. Matern. Fetal Neonatal Med. 2019, 32, 1368-1377. [CrossRef]

19. Foo, F.L.; McEniery, C.M.; Lees, C.; Khalil, A. Assessment of Arterial Function in Pregnancy: Recommendations of the International Working Group on Maternal Hemodynamics. Ultrasound Obs. Gynecol. 2017, 50, 324-331. [CrossRef]

20. Laurent, S.; Boutouyrie, P.; Asmar, R.; Gautier, I.; Laloux, B.; Guize, L.; Ducimetiere, P.; Benetos, A. Aortic Stiffness Is an Independent Predictor of All-Cause and Cardiovascular Mortality in Hypertensive Patients. Hypertension 2001, 37, 1236-1241. [CrossRef] [PubMed]

21. Laurent, S.; Katsahian, S.; Fassot, C.; Tropeano, A.I.; Gautier, I.; Laloux, B.; Boutouyrie, P. Aortic Stiffness Is an Independent Predictor of Fatal Stroke in Essential Hypertension. Stroke 2003, 34, 1203-1206. [CrossRef] [PubMed]

22. Boutouyrie, P.; Tropeano, A.I.; Asmar, R.; Gautier, I.; Benetos, A.; Lacolley, P.; Laurent, S. Aortic Stiffness Is an Independent Predictor of Primary Coronary Events in Hypertensive Patients: A Longitudinal Study. Hypertension 2002, 39, 10-15. [CrossRef] [PubMed]

23. Mitchell, G.F.; Hwang, S.J.; Vasan, R.S.; Larson, M.G.; Pencina, M.J.; Hamburg, N.M.; Vita, J.A.; Levy, D.; Benjamin, E.J. Arterial Stiffness and Cardiovascular Events: The Framingham Heart Study. Circulation 2010, 121, 505-511. [CrossRef] [PubMed]

24. Palatini, P.; Casiglia, E.; Gasowski, J.; Głuszek, J.; Jankowski, P.; Narkiewicz, K.; Saladini, F.; Stolarz-Skrzypek, K.; Tikhonoff, V.; Van Bortel, L.; et al. Arterial Stiffness, Central Hemodynamics, and Cardiovascular Risk in Hypertension. Vasc. Health Risk Manag. 2011, 2011, 725-739. [CrossRef] [PubMed]

25. Lee, J.-G.; Joo, S.-J. Arterial Stiffness and Cardiovascular Risk. Korean J. Intern. Med. 2019, 34, 504-506. [CrossRef]

26. Ogola, B.O.; Zimmerman, M.A.; Clark, G.L.; Abshire, C.M.; Gentry, K.M.; Miller, K.S.; Lindsey, S.H. Sex Differences in Cardiovascular and Cerebrovascular Physiology, Disease, and Signaling Mechanisms: New Insights into Arterial Stiffening: Does Sex Matter? Am. J. Physiol. Heart Circ. Physiol. 2018, 315, H1073-H1087. [CrossRef]

27. Mattace-Raso, F.U.S.; Van Der Cammen, T.J.M.; Hofman, A.; Van Popele, N.M.; Bos, M.L.; Schalekamp, M.A.D.H.; Asmar, R.; Reneman, R.S.; Hoeks, A.P.G.; Breteler, M.M.B.; et al. Arterial Stiffness and Risk of Coronary Heart Disease and Stroke: The Rotterdam Study. Circulation 2006, 113, 657-663. [CrossRef]

28. Mzayek, F.; Sherwin, R.; Hughes, J.; Hassig, S.; Srinivasan, S.; Chen, W.; Berenson, G.S. The Association of Birth Weight with Arterial Stiffness at Mid-Adulthood: The Bogalusa Heart Study. J. Epidemiol. Community Health 2009, 63, 729-733. [CrossRef] 
29. World Medical Association. World Medical Association Declaration of Helsinki: Recommendations Guiding Physicians in Biomedical Research Involving Human Subjects. JAMA J. Am. Med. Assoc. 1997, 277, 925-926. [CrossRef]

30. Devices-TensioMed \& Arterial Stiffness. Available online: https://www.tensiomed.eu/devices/ (accessed on 1 June 2020).

31. EUR-Lex-32016R0679-EN-EUR-Lex. Available online: https://eur-lex.europa.eu/eli/reg/2016/679/oj (accessed on 1 June 2020).

32. Vermeersch, S.J.; Dynamics, B.; Society, L. Determinants of Pulse Wave Velocity in Healthy People and in the Presence of Cardiovascular Risk Factors: ‘Establishing Normal and Reference Values. Eur. Heart J. 2010, 31, 2338-2350.

33. La Rocca, H.-P.B. Towards applicability of measures of arterial stiffness in clinical routine. Eur. Heart J. 2010, 31, 2320-2322. [CrossRef] [PubMed]

34. Kim, J.; Song, T.J.; Song, D.; Lee, K.J.; Kim, E.H.; Lee, H.S.; Nam, C.M.; Nam, H.S.; Kim, Y.D.; Heo, J.H. Brachial-Ankle Pulse Wave Velocity Is a Strong Predictor for Mortality in Patients with Acute Stroke. Hypertension 2014, 64, 240-246. [CrossRef] [PubMed]

35. Ki, Y.J.; Choi, D.H.; Lee, Y.M.; Lim, L.; Song, H.; Koh, Y.Y. Predictive Value of Brachial-Ankle Pulse Wave Velocity for Long-Term Clinical Outcomes after Percutaneous Coronary Intervention in a Korean Cohort. Int. J. Cardiol. 2014, 175, 554-559. [CrossRef] [PubMed]

36. Cruickshank, K.; Riste, L.; Anderson, S.G.; Wright, J.S.; Dunn, G.; Gosling, R.G. Aortic Pulse-Wave Velocity and Its Relationship to Mortality in Diabetes and Glucose Intolerance: An Integrated Index of Vascular Function? Circulation 2002, 106, 2085-2090. [CrossRef] [PubMed]

37. Blacher, J.; Guerin, A.P.; Pannier, B.; Marchais, S.J.; Safar, M.E.; London, G.M. Impact of Aortic Stiffness on Survival in End-Stage Renal Disease. Circulation 1999, 99, 2434-2439. [CrossRef] [PubMed]

38. Lynch, M.M.; Amoozegar, J.B.; McClure, E.M.; Squiers, L.B.; Broussard, C.S.; Lind, J.N.; Polen, K.N.; Frey, M.T.; Gilboa, S.M.; Biermann, J. Improving Safe Use of Medications During Pregnancy: The Roles of Patients, Physicians, and Pharmacists. Qual. Health Res. 2017, 27, 2071-2080. [CrossRef]

39. Babiker, A.; El Husseini, M.; Al Nemri, A.; Al Frayh, A.; Al Juryyan, N.; Faki, M.O.; Assiri, A.; Al Saadi, M.; Shaikh, F.; Al Zamil, F. Health Care Professional Development: Working as a Team to Improve Patient Care. Sudan. J. Paediatr. 2014, 14, 9-16.

40. Yannoutsos, A.; Bahous, S.A.; Safar, M.E.; Blacher, J. Clinical Relevance of Aortic Stiffness in End-Stage Renal Disease and Diabetes: Implication for Hypertension Management. J. Hypertens. 2018, 36, 1237-1246. [CrossRef]

41. Burton, G.J.; Yung, H.W.; Cindrova-Davies, T.; Charnock-Jones, D.S. Placental Endoplasmic Reticulum Stress and Oxidative Stress in the Pathophysiology of Unexplained Intrauterine Growth Restriction and Early Onset Preeclampsia. Placenta 2009, 30, 43-48. [CrossRef]

42. Chaiworapongsa, T.; Chaemsaithong, P.; Yeo, L.; Romero, R. Pre-Eclampsia Part 1: Current Understanding of Its Pathophysiology. Nat. Rev. Nephrol. 2014, 10, 466-480. [CrossRef]

43. Savvidou, M.D.; Hingorani, A.D.; Tsikas, D.; Frölich, J.C.; Vallance, P.; Nicolaides, K.H. Endothelial Dysfunction and Raised Plasma Concentrations of Asymmetric Dimethylarginine in Pregnant Women Who Subsequently Develop Pre-Eclampsia. Lancet 2003, 361, 1511-1517. [CrossRef]

44. Beck, D.T.; Martin, J.S.; Casey, D.P.; Braith, R.W. Exercise Training Reduces Peripheral Arterial Stiffness and Myocardial Oxygen Demand in Young Prehypertensive Subjects. Am. J. Hypertens. 2013, 26, 1093-1102. [CrossRef] [PubMed]

45. Iurciuc, S.; Avram, C.; Turi, V.; Militaru, A.; Avram, A.; Cimpean, A.M.; Iurciuc, M. Physical Training, Hemodynamic Parameters and Arterial Stiffness: Friends or Foes of the Hypertensive Patient? In Vivo 2016, 30, 521-528.

46. Crişan, S.; Petrescu, L.; Lazăr, M.A.; Văcărescu, C.; Nicola, A.R.; Cozma, D.; Mornoş, C.; Luca, C.T. Reduced Ejection Fraction Heart Failure-New Data from Multicenter Studies and National Registries Regarding General and Elderly Populations: Hopes and Disappointments. Clin. Interv. Aging 2018, 13, 651-656. [CrossRef]

47. Beetham, K.S.; Giles, C.; Noetel, M.; Clifton, V.; Jones, J.C.; Naughton, G. The Effects of Vigorous Intensity Exercise in the Third Trimester of Pregnancy: A Systematic Review and Meta-Analysis. BMC Pregnancy Childbirth 2019, 19, 281. [CrossRef] 
48. Cavalcante, J.L.; Lima, J.A.C.; Redheuil, A.; Al-Mallah, M.H. Aortic Stiffness: Current Understanding and Future Directions. J. Am. Coll. Cardiol. 2011, 57, 1511-1522. [CrossRef]

49. Dragan, S.; Buleu, F.; Christodorescu, R.; Cobzariu, F.; Iurciuc, S.; Velimirovici, D.; Xiao, J.; Luca, C.T. Benefits of Multiple Micronutrient Supplementation in Heart Failure: A Comprehensive Review. Crit. Rev. Food Sci. Nutr. 2019, 59, 965-981. [CrossRef]

50. Vamvakis, A.; Gkaliagkousi, E.; Triantafyllou, A.; Gavriilaki, E.; Douma, S. Beneficial Effects of Nonpharmacological Interventions in the Management of Essential Hypertension. Jrsm Cardiovasc. Dis. 2017, 6, 204800401668389. [CrossRef]

51. Stoicescu, M.; Csepento, C.; Muţiu, G.; Bungǎu, S. The Role of Increased Plasmatic Renin Level in the Pathogenesis of Arterial Hypertension in Young Adults. Rom. J. Morphol. Embryol. 2011, 52, 419-423.

52. Vesa, C.M.; Popa, L.; Popa, A.R.; Rus, M.; Zaha, A.A.; Bungau, S.; Tit, D.M.; Corb Aron, R.A.; Zaha, D.C. Current Data Regarding the Relationship between Type 2 Diabetes Mellitus and Cardiovascular Risk Factors. Diagnostics 2020, 10, 314. [CrossRef]

53. Fujime, M.; Tomimatsu, T.; Okaue, Y.; Koyama, S.; Kanagawa, T.; Taniguchi, T.; Kimura, T. Central Aortic Blood Pressure and Augmentation Index during Normal Pregnancy. Hypertens. Res. 2012, 35, 633-638. [CrossRef] [PubMed]

(C) 2020 by the authors. Licensee MDPI, Basel, Switzerland. This article is an open access article distributed under the terms and conditions of the Creative Commons Attribution (CC BY) license (http://creativecommons.org/licenses/by/4.0/). 